\title{
Evaluación del efecto de un biofertilizante ligado a un soporte orgánico mineral en un cultivo de lechuga en la Sabana de Bogotá bajo condiciones de invernadero
}

\section{Evaluation of the effect of a biofertilizer linked to a mineral organic substrate on lettuce grown under greenhouse conditions on the Bogota Plateau}

DIANA EDITH CASTELLANOS S.1

JOSÉ MARÍA RINCÓN M. ${ }^{2}$

HELIODORO ARGUELLO A. ${ }^{3,4}$

Cultivo de lechuga en la Sabana de Bogotá.

Foto: J.M. Rincón M.

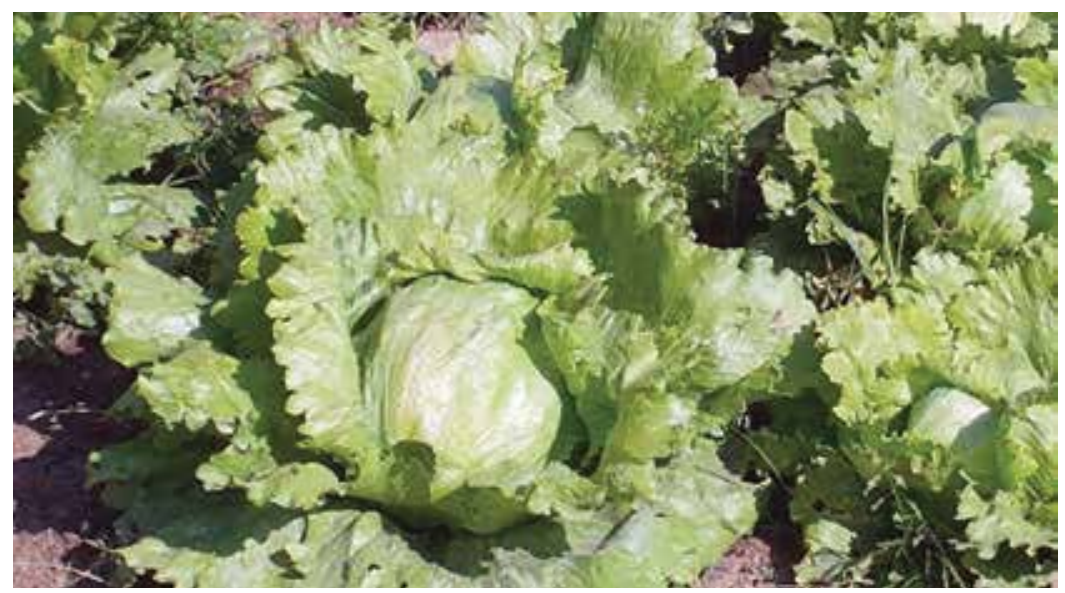

\section{RESUMEN}

Se evaluó el efecto a nivel de invernadero de un biofertilizante integrado en soporte orgánico mineral, en un cultivo de lechuga, var. Batavia, en la Sabana de Bogotá. Se evaluaron cinco tratamientos cada uno con 22 plantas así, compost + biofertilizante (T1), biofertilizante en soporte orgánico mineral (T2), biofertilizante común (T3), fertilizante químico (T4) y testigo absoluto (T5). Se realizaron muestreos de tipo microbiológico (conteo de poblaciones microbianas cultivo dependientes) en tres tiempos diferentes 25,46 y 68 días. Adicionalmente se realizó un muestreo de tipo agronómico al día 68 de las hojas (longitud, área foliar, peso fresco y seco) y raíces (longitud, peso fresco y seco). Los resultados indicaron, que en los tratamientos compost + biofertilizante y biofertilizante en soporte orgánico mineral, así como en el fertilizante químico se evidenció un efecto importante, en cuanto a los parámetros agronómicos valorados en las plantas, en comparación con los otros tratamientos. Sin embargo, no se observaron variaciones significativas en las poblaciones de microorganismos cultivo dependientes evaluadas.

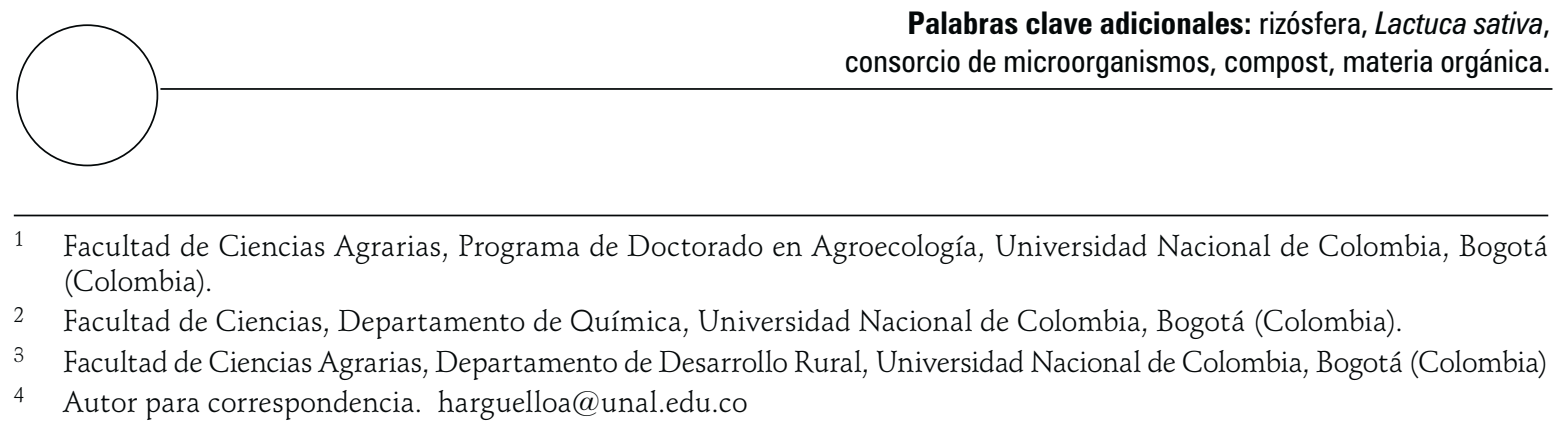

